\title{
Maritime Co-operation among South Atlantic Countries and Repercussions for the Regional Community of Security Practice
}

\author{
Sabrina Evangelista Medeiros* \\ William de Sousa Moreira**
}

\begin{abstract}
This paper aims to examine the importance of co-operation for maritime security in the South Atlantic, focusing on the relationship between the national and sub-regional institutions that have leveraged this process, especially those from Brazil. For this purpose, the diagnosis addresses the debates around the contemporary roles of the navy and the importance of international cooperation for its mission accomplishment, highlighting the tasks judged as subsidiary, among them being that of maritime traffic control. The alignment of these co-operative activities with foreign policy and national defence projects can be seen through the navy's participation in multilateral cooperation projects involving South America, particularly the Co-ordination for the South Atlantic Maritime Area (CAMAS). The research detects the existence of a particular model of a community of security practice in which national and sub-regional institutions have been generating an important maritime co-operative system, which is more stable than in other areas of co-operation in the same region.
\end{abstract}

Keywords: Co-operation; Maritime Security; Maritime Traffic Control; Navy; South Atlantic

\section{Introduction}

The oceans are vital for humanity in many senses. Used to convey wealth, military forces, people, and knowledge, their magnitude unites much more than it divides. In the last two centuries, technology has significantly widened the span of interactions between humans and the sea, extending the limits of exploration and exploitation to an unprecedented level, for better or for worse.

Amazing quantities of large and sophisticated infrastructure have been developed, deployed, and positioned either on the surface, underwater, or on the seabed. New and

\footnotetext{
* Naval War College, Rio de Janeiro-RJ; Brazil; sabrinamedeiros@yahoo.com.

** Naval War College, Rio de Janeiro-RJ; Brazil; williamsm2k@gmail.com.
} 
increasingly autonomous technologies have replaced humans where the environment makes human life difficult or impossible. Ranging from dynamic positioning systems to remotely operated vehicles, the fast-developing science, and its applications, stimulates figments on the future of the seas. A growing population in a globalised world puts pressure on the oceans, as the demands for energy, food, raw materials, transport, and security increase. Consequently, more actors are becoming involved in deploying oil and gas rigs, sea mining exploration platforms, fishery control systems, communication cables, ships of all kinds, and so on. Such an increase creates a need for improved control.

The marine environment has historically been an arena for power struggles, providing the setting for warfighting, conquering, colonising, subjugating, trafficking, smuggling, and the like. So, to establish an intervention capability to help maintain order at sea by means of force (or threat thereof), navies were built to defend national interests, and they have increasingly gained importance by projecting state military power at sea.

Notwithstanding their very combatant nature, naval forces have also gained, over time, a peculiar character. Despite their role as instruments of force and coercion, warships are often welcomed in other countries, especially if they are deployed, for instance, in an official capacity, to undertake 'goodwill' visits to promote friendly and co-operative diplomatic relations. In that sense, paradoxically, a naval combatant vessel can be a diplomatic tool to promote closer ties on a range of issues, rather than to threaten, whatever its size or range.

In this context, this paper aims to explore the co-operative potential of navies, first by presenting the theoretical framework that unveils their traditional ways of employment and, subsequently, by exploring the current perspective on the core functions of navies, their roles in facing the new challenges of the contemporary world, and the prospects for co-operation that affect international defence and security systems in the South Atlantic.

In order to substantiate our endeavour, it seems appropriate to address the theoretical approach to maritime co-operation and how it can enhance defence and security in both coastal and international waters, particularly in the South Atlantic. The perspective is that maritime co-operation has a limited institutional framework and structure to deal with the challenges presented. On the other hand, the challenges in co-ordinating and achieving a consistent maritime regime led sectoral-level governmental organisation to deal with regional demands, leveraging on their co-operative ties, build around the need to address common problems, especially in the South Atlantic Area.

After discussing the theoretical debate on the participation of navies in diplomacy and other peaceful roles, we turn our focus to look at how maritime co-operation can be an important nexus for regional regimes, possibly constituting a community of security practice. Thereafter, we offer empirical evidence of this ongoing movement and pattern which involves the most important actors bordering the South Atlantic coast. In that sense, this research describes the South American roots of the historical path representing that co-operation, depicting its relationship with inter-American co-operation and across the South Atlantic. We argue that regional engagement on maritime co-operation issues can be a way to suppress or reduce security challenges, in an effort that combines safety and security ${ }^{1}$ community developments. 
To this end, we are going to show how created regimes, most notably the Co-ordination for the South Atlantic Maritime Area - Coordenação da Área Marítima do Atlântico Sul (CAMAS) - can constitute, through a peaceful role, a growing security community with substantive practices and initiatives, and that may provide a possible channel to develop agreements and to strengthen South-South co-operation, without competing with other regional efforts, while being a possible focal point for multiple projects.

\section{Navies, diplomacy, and co-operation}

The role of navies has long been studied by strategists and scholars who have built typologies useful to understanding and mapping the tasks and uses assigned to and performed by naval forces. It is, however, appropriate to visit the available theoretical support to clarify the different levels and forms of the use of force at sea. Existing literature, mainly coming from the 'Great Powers' that continuously invest in sea power to support their global governance aspirations, values the use of military force at sea above all other roles. James Cable's 'gunboat diplomacy' approach excelled in that purpose (Cable 1977).

Ken Booth (1977: 15), for instance, stated that humans use the seas for three purposes: the transit of goods and people; the passage of military force either for diplomacy or against targets; and the exploitation of resources. Under this approach, Booth suggested that a navy has three functions: military, diplomatic, and policing. The diplomatic role is associated with the use of force in support of a country's overall negotiating position. In that sense, the use of navies is intended to do the following: to negotiate from a position of strength; to help friendly governments facing threats; to demonstrate power as a kind of subliminal message; and to maintain a reputation in the sense of building a favourable image of the country. The military role refers to the use or threat of the use of force. In that sense, a navy must be able to undertake the conventional deterrence and defence posture in peacetime; in wartime, it should be able to exercise sea control to achieve its assigned mission. The policing role may include coastal and surveillance responsibilities (with characteristics more akin to policing than military engagement) and the formation and consolidation of the nation, such as providing humanitarian relief and aid following natural disasters. Naval forces can, and do, also provide some contribution to the development of coastal and inland regions in developing nations (Booth 1977: 16).

Eric Grove suggested, at the end of Cold War, a new design for the use of the sea triangle, by imagining each edge as circles, allowing some overlap of the roles, depending on the geostrategic context. A certain naval event, for instance, could be a common factor in more than one role, or all of them. In that case, they could draw three circles representing the conflict, the national interest, and law and order at sea, which would overlap, so creating common areas of contact (Grove 1990) useful for further analysis.

Geoffrey Till (1994) reinforced the notion of navies as important state policy instruments. He conceived that the future of naval power would be based on three work streams: warfighting against high-power enemies or 'less serious' ones; naval diplomacy, which can be applied coercively to build alliances, or to provide international assistance; and, good 
order at sea. In the latter, the author states that many auxiliary functions depend on navies, such as the pursuit of pirates, smugglers, and drug traffickers; rescue operations; and other collaborations with the civil power.

More recently, Till (2013:35) has highlighted the importance of the link between navies and global security, arguing that 'Seapower is at the heart of the globalisation process in a way in which landpower and airpower are not, merely because the system is based primarily on sea transportation.' In addressing this theme, the strategist introduced the expression 'post-modern navies', corresponding to what he calls post-modern states, those developed countries that are 'acutely aware of the centrality of general maritime security to the efficient operation of a globalised sea-based trading system.' That serves to emphasise the vital maintenance of international maritime security, 'through the protection of good order at sea.' In that sense, he suggested that the post-modern roles of navies be 'sea control, expeditionary operations, stability/humanitarian assistance, inclusive good order at sea, and cooperative naval diplomacy' (Till 1994, 2013). This last role is of particular relevance for the present study since maritime co-operation has gained crucial importance in the defence of the sea-based trading system, stimulating states and navies to be outward looking in terms of international security.

In a similar vein, Christian Le Mière extended the academic effort to align the use of force at sea to the determinants of the 21st century. Although the original strict approach of gunboat diplomacy may seem outdated, that subliminal idea is still used in different ways by both developed and emerging countries. Le Mière highlights the difference between naval diplomacy and maritime diplomacy, valuing the latter as a way of incorporating other non-military actors, like specialised agencies and civilian services, into that discussion. In some parts of the world, those actors also play a relevant role in maritime governance, with diplomatic effects (Le Mière 2014).

Those authors have in common the understanding that navies are political instruments par excellence that may be used in different ways to support, sustain or strengthen the state's foreign policy. They recognise the dominant military role of navies, but also new responsibilities in the contemporary world. It is important, however, to take into account their contextual and analytical frameworks, inspired by first-class navies from the 'Great Powers', although they often consider in their literature the smaller fleets. As Baylis, Wirtz and Gray (2013) warn, one of the challenges for consistent strategic thinking is to avoid ethnocentric approaches, often expressed in a vast foreign Anglophone literature that informs the strategic reflexion. Naturally, those authors have developed their world visions based on their culture and conditions of life and education, which include political, social, economic and strategic contexts. As Booth stated in his extensive study in Strategy and Ethnocentrism (1979), this means all that may shape mindsets and, consequently, influence the strategic perceptions (or misperceptions) related to threats, opportunities, defence needs, and the like (Booth 1979).

On that basis, for the developing countries, it is important to value and properly weight some aspects, like the national character, the geographical, political, social, and economic circumstances, the robustness of a navy's capabilities, its strategic prospects, 
and the willingness and path for co-operation, among others. All those factors may give different meanings and solutions to analogous contexts described in the literature.

In terms of robustness, it is noteworthy that the South Atlantic-bathed countries rank four and above in Eric Grove's one-to-nine navy typology scale, topped by the tier-one US Navy. Although questionable, that scale from the early 1990s may help to assess the native sea power levels in the region. In other words, Southern seas navies' capabilities range from medium regional projection (adjacent oceans) to coastal defence (jurisdictional waters), down to a limited policing level, for the so-called 'token navies' (rank 9) (Grove 1990).

In an attempt to 'tropicalise' the debate, Moreira (1997) suggested an adjustment to Booth's classical triangle design (Figure 1), taking into account the developing countries' perspective and, moreover, by increasing the weight of the South American geostrategic context in the sea power strategic equation. Additionally, since the end of the Cold War, there has been a growing space for navies' peacetime activities in contexts other than wars, which amplifies opportunities for those medium and small navies.

Figure 1 - Ken Booth's use of the sea trinity

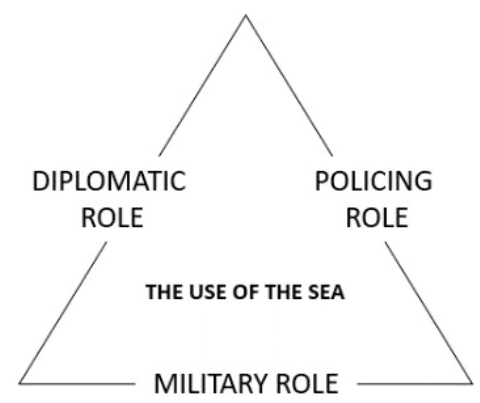

Source: Booth 1977

Figure 2 - Alternative approach

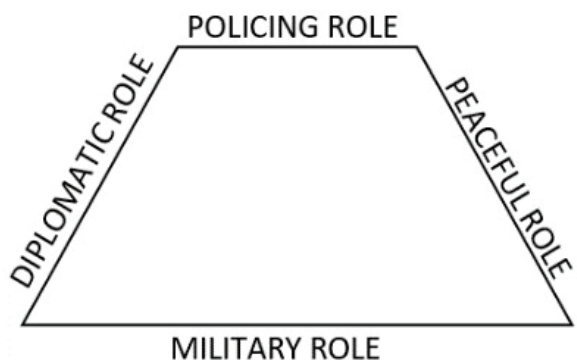

Source: Moreira 1997

Figure 2 shows the addition of a fourth edge ('peaceful role'), making it a trapezium. Without disregarding the main classic roles, notably the military one, that added edge 
highlights and reminds us of the use of navies in peaceful actions not strictly related to the use of force, as seems to be the case of the emerging countries located in the more stable region of the South Atlantic, far from the main conflict flashpoints in the world (Moreira 1997).

Additionally, the naval assets and combat platforms are technology and capital intensive and require considerable maintenance effort, which demands huge investments and creates budgetary pressures; it is essential, therefore, to offset those costs, in peacetime and within legal limits, by maximising their employment. That means political (in security and defence), economic, military (with appropriate training and preparation), and possible social activities contributing to society when and as requested, be it in support of a sailing race, to improve the safety of life and security at sea, to provide humanitarian and social assistance to the underprivileged people in far-off regions, or to alleviate disaster effects.

Also, navies are much more than military assets. They have highly qualified personnel and a huge infrastructure that includes naval bases, command and control installations on land, extensive communication and data networks, and considerable distribution points along the coastal areas, river basins, and lakes. They also take part or are represented in different commissions, councils, and boards that represent the states in national and international institutions concerning the governance of the seas. The International Maritime Organization (IMO) and the International Hydrographic Organization (IHO) are just two examples.

Another special characteristic of navies derives from the way of life at sea, which requires a similar education and training for seafarers from all nations and develops common views, language, terminology, and protocols on board ships. It facilitates understanding among personnel of varied nationalities and makes it possible to plan and execute missions involving different vessels, staffs, and idioms. On account of that, multinational naval operations have been not only viable but necessary ways of developing confidencebuilding measures and co-operation. In general, participants' goodwill helps to overcome the interoperability challenges that arise. For example, one can imagine the challenge of the IBSAMAR ${ }^{2}$ naval exercise that brings together at sea the Brazilian, South African, and Indian navies, where several different languages and accents need to be reconciled for operational voice communication. This notwithstanding, the acknowledged positive results of such operations help to unveil the collaborative potential of navies (Moreira 2016).

The geostrategic context in a region like the South Atlantic tends to stimulate collaboration. Far from the world's main conflict flash points, the region has plenty of natural resources and encompasses important sea lines of communications. In a globalised world, the security of the growing international trade by sea is of paramount importance. In addition, as Ásgeirsdóttir and Steinwand (2013) state, strong trade relations between the less robust military powers can reduce the risk of disputes between them and propagate the model in the region.

In that sense, once a common view is reached and room for co-operation at sea among states and their respective navies established, it is not difficult to promote a positive attitude to generating synergistic effects also using the land-based naval infrastructure, aimed 
at increasing the mutual benefits of, for instance, enhancing awareness of the maritime domain, an imperative in the 21 st century.

\section{Co-operation and communities of security practice}

Behind the sense of security, there is the capacity-building role of navies, focused on defending the respective state's interests at sea. That is why co-operation is essential for the current scenario, where organised crime and terrorist organisations make use of a range of maritime capabilities (Bradford 2005). The post-Cold War security environment overflows with different threats from diffuse sources, and that is why states are willing to commit themselves to co-operative regimes more than ever before.

Chapsos and Kitchen (2015) postulate that maritime security is one of the critical areas for enhancing security, because although technology has improved communications and effectively reduced distances, $70 \%$ of the world is covered by water and commerce is still crucially dependent on the oceans and freedom of the seas. So there are many elements behind this security space that are not simple to manage. NATO issued a document called Alliance Maritime Strategy 2011 (AMS) in which it concluded that co-operation and the AMS provided the only way to act against those identified gaps that affect NATO members nowadays.

Some authors of maritime studies have already observed how foreign relations can be conducted by expanding maritime co-operative efforts in terms of navy protocols and arrangements with other navies (Booth 1977; Chapsos and Kitchen 2015; Bradford 2005). However, more importantly, maritime co-operation can be equally based on functions which are not directly connected to military capabilities, but rather related to technical co-operation, enhancing protocols, demonstrations of friendship, and many activities that are mostly considered as subsidiary to the primary role of naval power.

While primarily focused on conflict and war, navies have also consolidated some functions which are mostly considered subsidiary. In this respect, while embracing functions dedicated to defence, navies have also had to comply with a list of duties not perceived as enablers of their main attributes. There are different terms to address those functions which fall outside of the norm, but here we call them subsidiary functions. The literature describes other functions of the armed forces as constabulary duties, configuring the police, and internal security roles related to good order at sea. Though activities associated with deterrence and war might represent a navy's principal responsibility, national defence demands the security of the seas as well as the safeguarding of merchant marine and shipping lanes, to say nothing of the problems surrounding territorial and maritime limits, which remain and which challenge regimes to improve their effectiveness.

Geoffrey Till (2006) observes that, even though there is a common notion of contemporary threats, there are different perceptions depending on how individual actors are affected by those threats. As mentioned earlier, there is a chance of ethnocentric biases resulting in different views of strategic issues. In this respect, behaviour and strategic planning will be differentiated not only by the threat significance but also by the particular views and procedures regarding defence and security vulnerabilities. However, states have 
been pushed into international arrangements no matter what their priorities are and, for that, there is the effect of diminishing vulnerabilities through the improvement of the underdeveloped states' capacities by means of direct or indirect foreign aid and large sunk investments.

On the other hand, one cannot avoid participating in the multilateral interest of maintaining good order at sea. As an example, the United Nations Convention on the Law of the Sea (1982) defines, in Article 42, that there is a presumed obligation of co-operation if the users are states that are established on straits and there is the permanent need to safeguard the seas. So co-operation is not a matter of voluntarism based on a belief of outgrowing such obligations. There is a willingness to co-operate because one state's system may become more stable due to combined actions and the trust-building mechanisms (Axelrod 1984). That may happen as Till stated:

[T] he response to threats, as a result, may be of extreme importance to the understanding of how the maritime system is changing and how strategies may move together. In this regard, the tools or the means are not as important as the policies implemented, which should be of an amplified scope (Till 2006: 13; authors' translation).

Till addresses three possible forms of response to the international maritime environment where there are significant threats. The first would be a traditional enforcement of power, with a navy's capacities at the disposal of the state's strategy. The second would be based on the conditions of controlling the state's maritime area, reinforcing its domain. The third response to threats is what he calls maritime consensus, where interests coexist, converge, or conflict. Lastly, in possible support of the third point, one can cite the way coastguards, where they exist, and navies deal with the responsibility of maintaining good order of the oceans' systems of governance (Till 2006).

Using this scheme to better understand contemporary naval roles regarding co-operation, we can state that sharing capabilities may be an example of the second and third strategies defended by Till (2006), whenever the threat is the same. We can assume that most of the aspects noted by Till can directly connect to an efficient co-operation strategy devoted to the oceans' security.

About the theme, Chapsos observed that despite the intention of NATO and EU state delegations to enhance co-operation, a common definition for that concept of maritime security had not been reached yet. Despite that, security practices have emerged and been adopted by different communities that have given birth to the expression 'communities of security practices' as a spontaneous and functional solution (Chapsos and Kitchen 2015). Those communities of security practices have been receiving stimulus from areas outside of their respective covered territories, because the insecurity that inhibits the regimes may come from points of instability elsewhere and can affect the large economies that concentrate their interests on sea-based commerce.

So a particular interest of maritime security is that the oceans are regulated by different sources of rights, which are supported by the recent institutional framework of the United Nations Convention on the Law of the Sea (UNCLOS 1982). That differs from 
those challenges affecting territories due to ever-present sovereignty issues, even influencing global trade. Any point at sea can be of interest to the state, even if far away from its immediate borders, once maritime trade shipping lanes spread beyond it and have a huge representation to the equilibrium of the international system.

Structures and mechanisms aim at meeting the demands related to the governance of the oceans. Even though navies are constituted primarily for defence purposes, there are some activities developed for security and safety, which requires navies' international and national arrangements to include other institutions and agencies. Ergo, the best representation of those co-operative mechanisms would be a crossing structure among navies and their institutional counterparts, constituting communities of security practices (Chapsos and Kitchen 2015). That is because, where there are navies, there can also be coastguards, port authorities, and co-operation regimes that are responsible for overseeing and working on security and safety occurrences. Hence, regime co-operation is crucial to security and safety procedures, even though not deeply institutionalised and without autonomy. Accordingly, the diplomatic role may guarantee that a navy can strengthen political and defence relations, promoting regional stability. Adjacent to those roles, the subsidiary functions are quite close to the others where they approach coastal defence, Exclusive Economic Zone (EEZ) security, and good order at sea.

Because resources are scarce and limited, one must consider that concentrating efforts on creating interstate institutions may be very expensive (Gopalakrishnan 2000), whereas taking advantage of the institutions already in place at the national level could benefit cooperation with the use of already existing and available resources. Not surprisingly, the number of maritime agreements grew rapidly using inter-agency co-operation as a way to expand knowledge and to provide awareness of developments at sea, considering that most of the vulnerabilities may have international consequences (Le Mière 2014; Nordquist and Norton 1999).

Following UNCLOS (1982), the common perspective on how states should achieve peace and security was understood through co-operation and compliance with the legal order for the seas and oceans. Within this co-operative legal compromise, states would agree on the organisation of the 'waters', including river mouths, internal waters, and bays, as well as ports, facilities, ships, registration, regulations of goods and people, and the conservation of natural resources.

With the developments that have arisen since the end of the Cold War, the reorganisation of the regimes was an imperative to the new perspectives and arrangements interposed. That seems to be the case with NATO, as it focuses on collective defence, encompassing many different powers. Therefore, reaching consensus on priorities is a challenge (Dorman and Kaufman 2010). In other words, Western states have built different points of view on what should be the priorities qualified by different perceptions of threats, possibly driven by the aforementioned ethnocentric approaches. The core meaning of Dorman and Kaufman's assertion is that it is difficult to establish co-operation where Great Powers are involved, and different weights and measures are applied in observation to threats that can affect them, as in the case of NATO. 
Regimes, then, may emerge as a function of the movements around one theme, and their constituency may depend on how the institutional progress happens. Building communities of security practices in the new century was, in our interpretation and according to the functionalist theory approach, unavoidable even when capabilities and resources were limited and disproportional. Once the spectrum of the co-operation counts on a common and shared repertoire, we can say something is moving because of this valued shared space where security communities have emerged in terms of maritime security, at least since the beginning of this century (Adler 2000, 2008). When talking about those security communities in Asia (Bradford 2005) or Africa (Bueger 2013), it is possible to conclude that in none of those geopolitical spaces did communities of security practices arise without dispute or with total consensus. Also, those communities can be framed by overlapping institutions that are reinforced, transformed, or adapted to renewed strategies, progressively shaping policies dealing with new paradigms and dilemmas.

The South Atlantic would not be different from the Asian or African cases where security communities are considered imperfect, but there is still a certain scepticism that can be found in the literature to note the establishment of a regional complex for the case mentioned. Nevertheless, an economic motivation among actors seems evident and contributes to reinforcing the need for a co-operative interaction. The reasons for the occurrence of this approach on the issue of maritime security through the challenges encountered around the Gulf of Guinea, according to Ines Sousa, can be summarised in the section:

[...] Although there is coordination and cooperation among countries located in both hemispheres to tackle maritime security issues in the region, as in the case of the piracy in the Gulf of Guinea, our reading is that this type of initiative normally occurs in circumstances where general economic interests are at stake - thus, not indicating the emergence of a wider Atlantic connection (Sousa 2014: 19).

The recognition that the South Atlantic is not a security community, even in its subregions, seems to be a consensus view among some of the experts (Sousa Neto 2014; Abdenur and Marcondes 2014). Instead, in the understanding of Abdenur and Danilo Souza Neto (2014: 6), 'an imagined community', whose reification brings concreteness and is an ongoing process, achieves better results for the enrolled states and began only a decade ago.

Next, we are going to point out the elements around an emerging community of security practices in the South Atlantic and based on maritime security, trying to put in evidence the efforts that are essential to the alignment of these co-operative tools.

\section{Maritime co-operation in the South Atlantic}

As part of the Navy Commander's subsidiary functions in Brazil, the Complementary Law (CL) No 97/1999 (as amended by CL 117/2004 and CL 136/2010) assigns the following responsibilities: to guide and control merchant marine and defence-related ac- 
tivities; to provide for the safety of navigation at sea; to contribute to the formulation of national policies about the sea; and to implement, supervise, and control law compliance in co-ordination with the other federal or federative agencies, according to their respective responsibilities. These roles fall to the Brazilian Navy (BN) Commander, given that his position encompasses the functions of the National Maritime Authority, based on the above-cited legislation (Brazil, 1999).

In this sense, safety and security (both of which are encompassed by the Portuguese term 'segurança') are part of those responsibilities assigned to the Commander, including environmental protection and the safeguarding of human life at sea. According to the same legislation, there must be a permanent guarantee regarding safety and security, beginning with safety conditions at sea, where the components are accordingly identified. In this regard, the required conditions may be pursued through inspection of the identities of personnel, and of equipment and cargo, ranging from big ships to boats. The tracking of all sorts of information regarding the circulation of goods and people is essential to the performance of those described functions. Bear in mind that the safety of the seas is a condition for the internationalisation of global wealth, and a challenge to humanity.

Countries rely on navies to protect their jurisdictional waters, granted by the provisions of the UNCLOS. In the case of Brazil, that task assumes enormous proportions. Its littoral is $8,500 \mathrm{~km}$ long, and the sum of the EEZ plus the continental shelf areas totals 4.5 million $\mathrm{km}^{2}$, about half the land area of the country. Also, 29,000 km of rivers, mainly in the Amazon and Paraguay-Parana basins, drive the Atlantic influence inward to the continental mass (Moreira 2016). Such a huge area contains vast amounts of natural resources, including fresh water supplies, oil and gas reserves on land and at sea, mineral raw materials, fishing stocks, and biodiversity, among others, commodities that are all vital to the wealth of the nation.

Although far from the world's current conflict hotspots, such as those in the Middle East, Southeast Asia, and the China Sea, the South Atlantic region faces some of the socalled new threats, being a route for drug and human trafficking, smuggling, predatory fishing, piracy, armed robbery, and organised crime in general. This geostrategic context seems unique and requires concerted action among the countries of the South Atlantic region, i.e. proactive diplomacy and co-operative relations.

In that sense, most scholars, strategists, politicians, and defence experts acknowledge the diplomatic role of navies and their peaceful roles to the benefit of maintaining an equilibrium in the international system. Brazilian foreign policy is governed by constitutional principles like national independence, self-determination of peoples, non-intervention, equality among states, defence of peace, the peaceful settlement of conflicts, and co-operation among peoples for the progress of humanity.

Those universal principles are reflected in Brazilian foreign and defence policies, which in turn are based on traditional values that promote international engagement on a multilateral and co-operative basis. Aligned with those principles and others from the National Defence Policy and the National Strategy for Defence (Brazil, 2013), under the aegis of the Ministry of Defence, the Brazilian Navy holds multilateral and bilateral meet- 
ings with friendly countries' navies ${ }^{3}$. Those meetings contribute to building co-operation and confidence, with measures ranging from personnel exchanges on courses or staff assignments, symposiums, and seminars, through to complex multilateral naval operations such as the previously mentioned IBSAMAR. Another example is the partnership with Namibia ${ }^{4}$ to assist in the building of the naval wing of the country's Defence Forces - and the current efforts are also fostering relations with Cameroon.

Also, that long-standing posture has ensured the conditions for the development and maintenance of a merchant traffic control system, which will be addressed in the next section. It is worth noting that, in peacetime, the Brazilian Navy drives its contribution by the projection through co-operation, in other words, by developing relations and actions based on confidence and symmetry to the benefit of South Atlantic maritime security.

The South Atlantic conjuncture tends to stimulate new forms of ties among countries, sub-regions and regions. In that sense, Brazilian foreign policy has varied in its efforts towards the region, focusing on some institutional arrangements. In general, the South Atlantic arrangements can be categorised as follows: those within the United Nations scope - where the South Atlantic Peace and Cooperation Zone (ZOPACAS) plays a flexible role (Aguilar 2013); those within the South America region (MERCOSUR, CAMAS); those in West Africa (Maritime Organisation for West and Central Africa (MOWCA); the Interregional Co-ordination Centre, under ECCAS (Economic Community of Central African States), ECOWAS (Economic Community of West African States), and CGG (Commission of the Gulf of Guinea), and the African Union (UA)); and the extra-regional actors (US-AFRICOM; CPLP (Community of Portuguese Speaking Countries); and the European Union).

Although the above regimes are arguably the most visible, that does not reduce the importance of the institutions which may overlap with a more flexible structure. Even though with different levels of institution building and, eventually, different approaches, regimes devoted to the African and South American Atlantic coasts have been gathering an assortment of maritime initiatives. Nevertheless, their performance does not always entail sectored national institutions and thematic initiatives, such as the controlling of maritime activity plans and actions (Wambua 2009; Bueger 2013).

Defence co-operation in the Americas has grown steadily since the end of World War II, and includes the emergence of defence institutions to guarantee collective security among partners of the so-called Western Hemisphere. Although national institutions have varied over the last fifty decades, it is possible to say that no other regional defence institution has done more for the advancement of common protocols for the armed forces all over the continent than the Organization of the American States and associated institutions. That happens in the same way in the maritime security political field, but revealing different grades of institutionalisation (Medeiros 2015).

The so-called Plan para la Coordinación de la Defensa del Tráfico Marítimo Interamericano (CODEFRAMI - Maritime Traffic Defene Coordination Plan), initially called PLANDEFTRAMI (1959), was created and implemented under the auspices of the InterAmerican Defense Board, as a complement to the Inter-American Treaty of Reciprocal Assistance (TIAR) (Otto 2015). The principal objective of the plan is to co-ordinate those 
functions adherent to the control of the sea regarding safety and security with national navies. The plan observes functions related to directing, monitoring, and defending maritime traffic in the maritime areas around the Americas (Medeiros 2015).

That is why the plan divided the area into four: South Atlantic (Área Maritima do Atlântico Sul - AMAS); South Pacific (Área Marítima do Pacífico Sul - AMPAS); North Atlantic (Área Marítima do Atlântico Norte - AMAN); and, the North Pacific (Área Maritima do Pacifico Norte - AMPAN). Due to the limits of the scope, the implications for the co-ordination were overwhelmingly political, and compliance was not entirely achieved. In this respect, there were different understandings regarding the necessity and utility of the areas, and thus development of the institutionalisation processes occurred at varying levels.

Even though initiatives were created to provoke a firm co-ordination commitment, concerned with the division of the Americas' maritime area into four, the North Pacific and North Atlantic areas were maintained only in terms of documents, due to the United States' unilateral position on this matter. In the case of the South Pacific, the initiative was focused on maintaining a place to co-ordinate efforts in the maritime area, but the outcomes were limited by the still existing inland tensions. By contrast, in the South Atlantic Maritime Area (AMAS), while the South American countries did have a war preparedness directed to the South, the CAMAS or the Co-ordination of the AMAS succeeded.

Although there are ongoing operations that are heading towards commands outside of the South Atlantic Area, it is still important to observe the recently created incentives to a regional commitment in Africa, devoted to a common maritime strategy. If this is not the same focus as in South America - having a common maritime strategy - the alertness for the various maritime problems is of shared value. Those insecurity factors can be listed from IMO, explained by a Chatham House Report:

The wider maritime security issues that the IMO is concerned about are illegal, unregulated and unreported fishing, which is a massive problem and probably far more important in West Africa than piracy; and illegal trafficking of guns, oil, humans and stolen goods, which is another major factor affecting Africa's sustainable development. The fishing business in this area has an estimated value of \$10-23 billion. In most West African countries, this represents much of national incomes; moreover, fish provides over $50 \%$ of the edible protein consumed in the region. The current fishing levels off the coast of West Africa are unsustainable, and the destruction of the fishing grounds creates a security problem (Chatham House 2013: 16).

It is important to appreciate that whereas the South Atlantic countries experience different levels of insecurity, efforts to boost national, sub-regional, and regional institutions are all linked to the same threats and actions. Thus, technical co-operation - which includes training, sharing of technology, and the exchange of means and people - would 
be one of the most important fields for connecting partners in the South Atlantic Area (Aguilar 2013).

\section{Evidence of a shared repertoire}

In regard to boosting protocols, interoperability, and institutionalisation, undoubtedly the South Atlantic Maritime Area Coordination (CAMAS) has been the most successful partnership and constitutes a level of co-ordination that has progressed during recent years, marked by improvements in control systems. Those developments fall under the COMCONTRAM authority in Brazil, which is the Maritime Traffic Naval Control Command. The roles and challenges of the COMCONTRAM are based on exchanging messages (AMASSEC; ATRIA); receiving information from merchant ships, cruise liners, and fishing vessels (the Maritime Traffic Information System SISTRAM and the National Fishing Vessel Tracking Program PREPS); monitoring and assisting vessels (the Automatic Identification System MSSIS/AIS, which works near the territory); identifying long distance ships (LRIT); and deep water oil exploitation tracking (SIMMAP). In relation to the security procedures, the ISPS Code (International Ship and Port Facility Security Code) was adopted and amended under SOLAS (International Convention for the Safety of Life at Sea). That system stipulates mandatory and non-mandatory requirements for governments, port authorities, and ships, all with determinant positions to comply.

Initiatives that are worthy of note are those focused on the benefit of integrating systems at the regional and extra-regional levels. As a result of the joint exercises and rounds of talks, the service-oriented infrastructure for maritime traffic tracking (SMART) is progressively adding the Brazilian systems and information to the Mediterranean ones, led by the Italian Navy. The Wider Mediterranean Community (WMC) is counting not only on the Brazilian Navy but also on Singapore as part of the plan of optimising the control of maritime traffic, building a virtual platform for the interchange between the Brazilian System (SISTRAM) and the Mediterranean (VRMTC - Virtual Regional Maritime Traffic Centre). Figure 3 shows a broad view of the data system presentation. ${ }^{5}$ 


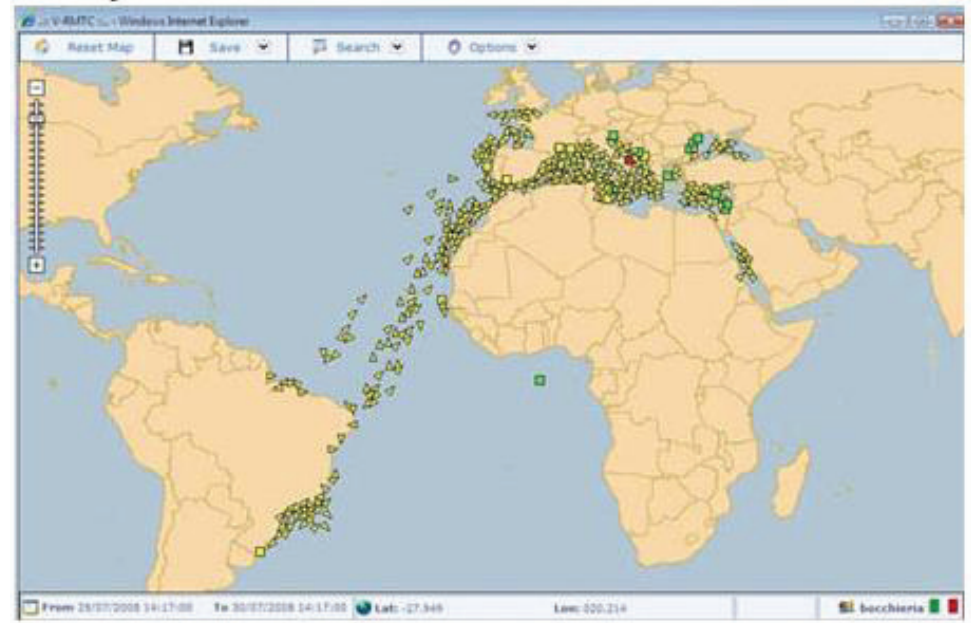

Source: BN Naval Command of Maritime Traffic Control (COMCONTRAM). At: https://www1.mar.mil.br/ comcontram/?q=V-RMTC [accessed on 10 March 2017].

Strengthening protocols is a way of guaranteeing that maritime commerce cannot be interrupted, and it may be critical to the surveillance of the most important powers whenever maritime security is not part of the possible control of the countries with lower capabilities. As pointed out by Ivan Luke (2013: 13): 'Protecting this critical peacetime economic link is a vital national interest and a pillar of global stability'.

Another example is the Trans-Regional Information Exercise, which permits countries to reinforce priorities and realign perspectives on how to concentrate efforts and share information contributing to the safety and security of peoples and the commerce of goods. Also, the Transoceanic Exercise as a Naval Control of Maritime Traffic (CNTM) is part of the refinement of the operational constraints for enhancing co-operation among the countries that form the Inter-American plan in the South Atlantic Maritime Area (AMAS). Figure 4 shows a picture of the SISTRAM data map. ${ }^{6}$ 
Figure 4 - Picture of the SISTRAM map

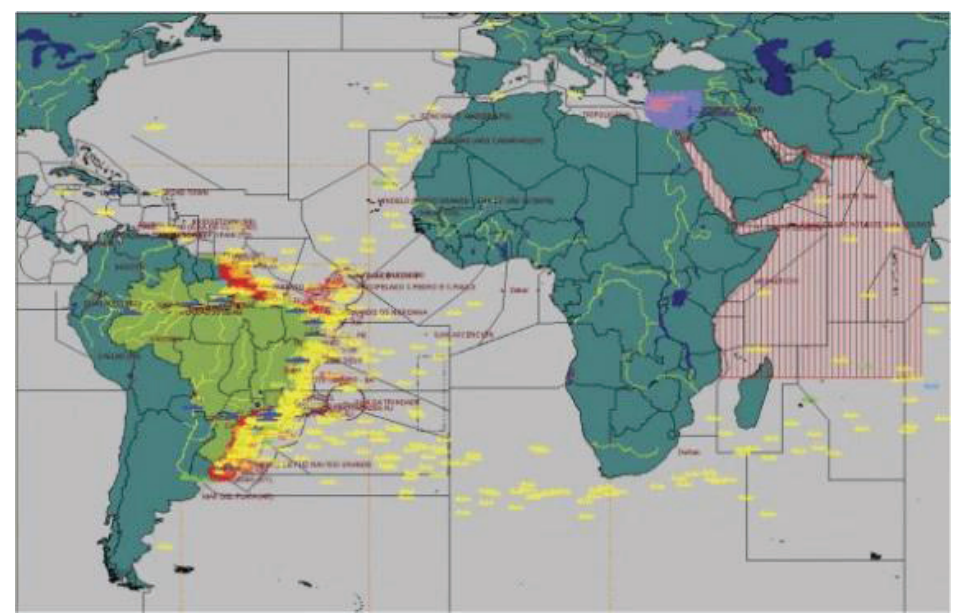

Source: Poder Naval. At: http://www.naval.com.br/blog/2014/02/05/inauguracao-do-novo-centro-de-controle-do-trafego-maritimo/ [accessed on 10 March 2017].

In June 2016, at the Brazilian Naval War College, co-ordinated by the Centre for Political and Strategic Studies (CEPE), a conference was organised with IMO sponsorship that included specialists and military/civilian representatives from countries inside and outside of the South Atlantic region. On this occasion, a simulation was performed based on a hypothetical case for the improvement of defence capabilities, and protocols focused on the safety and security of the countries' respective territorial seas (12 miles), contiguous zones (+12 miles), exclusive economic zones, and search and rescue areas (SAR). At the event, both the Maritime Control System and the War Game Simulation System (SSGN - Sistema de Simulação de Guerra Naval) were used, building ties that could shortly include other countries as sharing partners for protocols and support system.

As the first regional maritime controller, the Brazilian COMCONTRAN has already shared the Long-Range Identification, and Tracking (LRIT) system - through the Centro de Dados Regional LRIT do Brasil (CDRL Brasil) - with Uruguay and Paraguay, and is presently co-ordinating an equal sharing with Namibia and Angola. That represents longrange information accessibility in support of maritime control across the South Atlantic, which is dependent on the land-based capabilities and technologies available to each state and its respective organisations. 


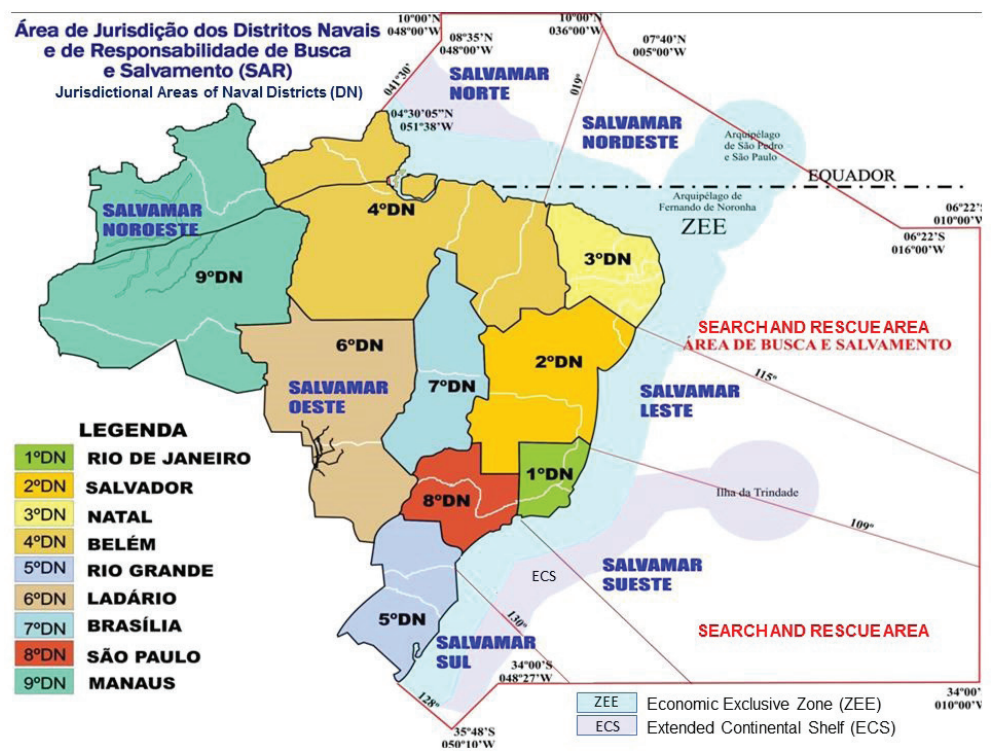

Source: Brazilian Navy - Salvamar Brazil. At: https://www.mar.mil.br/salvamarbrasil/areas.html (own translation and adaptation) [accessed on 10 March 2017].

Figure 5 broadly shows the jurisdictional waters and the extension of the SAR area. ${ }^{7}$ As is possible to observe (Figures 4 and 5), guaranteeing control of Brazil's jurisdictional waters may be undertaken more efficiently if there is the possibility of obtaining and accompanying real-time information, including from African partners. LRIT is a system that can provide information to contracting governments - as they are called - entitled to receive and send information through co-operative data centres. It is based on matching collaborative protocols, using the same codes, language, and reporting models, in accordance with the standards shared by the IMO. Under the International Convention for SOLAS of 1974, aimed at guaranteeing the safety of merchant ships, states have been obliged to comply with the safety norms and requirements, and to reinforce those procedures in ships of other flags. Efforts are being made to bring closer relations between Brazil and Cameroon, where the regional data centre has been installed for Central and West African countries (ICC - Interregional Coordination Centre). It is another important subregional institution that has been the basis for maritime co-operation and the building of a community of security practices.

Potential benefits from these new sources of co-operation between South America and Africa include a low-cost bridging mechanism, which is capabilities oriented and on a shared perspective of engagement, to purposes other than war, including peaceful roles, as suggested at the beginning of this paper. Nevertheless, the prospect of securing such capabilities as information and system sharing first requires closer relationships, which were previously ensured through the constitution of Co-ordination to the South Atlantic Maritime Area, fostering Brazilian investments in such endeavours. 
Guidance to maintaining the seas as being as safe and as secure as possible is the main purpose of the IMO mandate, and it is clear that safety has moved closer to security as the challenges in the maritime spaces may be even more complex than during war periods. We could say that procedures that favour maintenance of merchant shipping and commerce safety also help considerably the security challenges that affect the states. Even though the procedures may be different in each case, developing capabilities in terms of a joint information system is an efficient way to be prepared to deal with the security problems of the region. Therefore, enacting common procedures regarding safety and security reinforces capacities and mobilises interchange and integration. Triggered by an appropriate emergency warning report, for instance, one or more partners, whether from the region or not, can execute specialised tasks at sea in a timely fashion.

Under budget restrictions caused by the economic crisis or actors' underdevelopment, as Rohde and James (2004) have discussed, the agreements on information and systems sharing may be a great way to increase maritime awareness. Aiming at leveraging the control of the South Atlantic Area, CAMAS' experience and practice is evidence that, even when efforts are not completely executed, there can be an opportunity for continuing with another path, as it was not controlled by or dependent on the Inter-American Board.

Also, by proposing itself as the first regional controlling system, it has expanded the coverage from the original area of South America to across the Atlantic. It seems clear that the efforts in the America's South Atlantic tend to be more valuable and effective if there are the same correspondents and efforts in West Africa, and if regimes like CAMAS can reinforce and provoke that extra-region co-operative alignment.

\section{Final thoughts}

As distinct from the concept that navies are available for war purposes, there are messages sometimes 'neither explicitly announced nor implied, however, as they may be left entirely unsaid' (Le Mière 2014).

The perspectives on the use of force at sea and the roles of navies may be affected by ethnocentric biases, often expressed in foreign literature, and may significantly differ between hemispheres, regions, and countries. This paper has attempted to tropicalise the debate by bringing to it the realm of the medium and small navies, in the light of the conjuncture that prevails particularly in South America and the South Atlantic, a peaceful region.

The navies, in general, have not lost their main defence-oriented task. Nonetheless, we can perceive a progressive transformation of some of their activities, particularly when the geostrategic context sets the conditions for it, when there are constraints regarding economic resources and military capabilities, or where there is room for developing new forms of projection by means of co-operation, as seems to be the case of Brazil and other South Atlantic-bathed countries.

While there is a fertile ground for co-operation among major and small or 'token' navies, there are different ways to pursue it. In this article, we have tried to show how navies 
can have more duties regarding boundaries on military affairs, diplomacy, constabulary functions, and maritime security. Also, we observed what the Brazilian approach is on the theme and how it has been gathering support from South Atlantic countries for the benefit of security and safety at sea in the region.

The co-operation with African countries to face the Atlantic challenges was boosted by maritime diplomacy over the past few decades, particularly through arrangements among states with lower financial and material capacities, but with the diplomatic and political will to enhance ties. It is possible to affirm that the ties created among already installed sectoral-level governmental organisations are paramount for stability and peace in the South Atlantic, especially because naval forces, as a tool of foreign policy and diplomacy, are part of the legitimacy of this endeavour in which co-operation has been long lasting.

Because of the difficulties around creating other regimes and institutions in addition to those already in place, optimising and sharing capabilities seems to be a positive way of enhancing protocols and, ultimately, the sense of security, safety, and control in the South Atlantic. That is why we consider there to have been a useful practice in improving maritime security promoted through the latest advances in technology and the institutionalisation of protocols enhancing sharing and co-operation. Although conducted by old sectoral-level institutions such as CAMAS, it does permit a reconfiguration of the security architecture of the South Atlantic, reshaping diplomatic relations as the emergence of new communities of security practices, probably disfiguring the original purposes and framework of those entitled institutions.

In other words, regional engagement on maritime co-operation combining safety and security community developments can be a way to suppress or reduce the challenges of the 21 st century.

It is significant to note that South Atlantic co-operation has evolved around maritime co-operation, but not only that. Undoubtedly, so as to promote co-operation, improving maritime security and safety procedures may align a significant part of the state institutions' desire to mirror actions from all over those continents bordering the Atlantic.

\section{Notes}

1 In this article, 'security' broadly refers to the degree of absence of threats in the international system, while 'safety' mainly refers to the protection and safeguard of human life at sea. In the Portuguese language, both are encompassed by the word 'segurança', although one may also find the word 'salvaguarda' for human life safety.

2 IBSAMAR is an acronym derived from IBSA, the forum that brings together India, Brazil, and South Africa. This multinational naval exercise aims at strengthening friendship ties and joint deployments. It is also an opportunity to share professional experiences of the South Atlantic and to enhance naval cooperation. The first versions of the operation were held off the South African coast. Following a progressive process of development, the fifth exercise, IBSAMAR V (2016), took place for the first time in Indian waters. The Brazilian Defence White Paper (English version 2012: 110-111) provides more information on other multinational military and naval exercises (available at http://www.defesa.gov.br/arquivos/estado_e_ defesa/livro_branco/lbdn_2013_ing_net.pdf) Accessed on 5 November 2016.

The National Defence Policy sets the goals and the general political orientation for the national defence 
system. The National Strategy of Defence balances political goals, means, and available resources, providing guidance for force planning and the preparation of the Armed Forces. The Defence White Paper, aligned with those two cited documents, informs society and the international community of the general status, size, distribution, and budget of the military forces, among other information. In accordance with the general principles of Brazilian foreign policy, those documents value and stimulate military and naval co-operation, emphasising the worthiness of military diplomatic activities, including personal exchange, technical co-operation, and multinational naval operations and exercises. The same documents highlight the priority of the South Atlantic region. All three documents are revised quadrennially by the Government and sent to the Congress for discussion and ratification.

4 The naval co-operation efforts with Namibia mark another point regarding what is indicated in the previous endnote. They also evidence the potential of the military naval cooperation in support of foreign policy, as referenced in the Defence White Paper, p. 108. For further discussion on Brazil - Namibia cooperation impact on maritime security, see Seabra, 2016.

5 Available at: https://www1.mar.mil.br/comcontram/?q=V-RMTC. Accessed on 5 November 2016.

6 Available at: http://www.naval.com.br/blog/2014/02/05/inauguracao-do-novo-centro-de-controle-dotrafego-maritimo/. Accessed on 20 October 2016.

7 Further information about SAR is available at: https:/www.mar.mil.br/salvamarbrasil/index.html. Accessed on 5 November 2016.

\section{References}

Abdenur, Adriana and Danilo Marcondes de Souza Neto. 2014. 'O Brasil e as cooperação em defesa: a construção de uma identidade regional no Atlântico Sul'. Revista Brasileira Política International, 1 (57): 5-21.

Adler, Emanuel and Michael Barnett. 2000. 'Taking Identity and Our Critics Seriously', Cooperation and Conflict, 35 (3): 321-329.

Adler, Emanuel. 2008. 'The spread of security communities: communities of practice, self-restraint, and NATO's Post-Cold War Transformation'. European Journal of International Relations, 14 (2): 195-230.

Aguilar, Sérgio Luiz Cruz. 2013. 'South Atlantic: Brazil-Africa relations in the field of Security and Defense'. Austral: Brazilian Journal of Strategy \& International Relations, 2 (4): 47-68.

Ásgeirsdóttir, Áslaug and Martin Steinwand. 2013. 'Dispute Resolution Mechanisms and Maritime Boundary Settlements. Paper presented at the annual International Studies Association Conference, San Francisco, April 2013. [Online]. At: http://www.uni-heidelberg.de/md/awi/peio/asgeirsdottir steinwand_29.08.2013.pdf. [Accessed on 15 March 2016].

Axelrod, Robert. 1984. The Evolution of Cooperation. New York: Basic Book.

Batzenstein, Peter. 1996. 'Regionalism in Comparative Perspective'. Cooperation and Conflict 31 (2): 123-59.

Baylis, John, James J Wirtz and Colin S Gray. 2012. Strategy in the Contemporary World. 4th ed. London: Oxford University Press.

Booth, Ken. 1977. Navies and Foreign Policy. London: Routledge. 1979. Strategy and Ethnocentrism. London: Croom Helm.

Bradford, John. F. 2005. The growing prospects for maritime security cooperation in Southeast Asia. Newport: Naval War College. 
Brazil. Complementary Law (CL) No 97, 25 June 1999. Official Gazette of the Federative Republic of Brazil, Brasília, DF, no 187, 10 June 1999. Amended by CL No 117, of 02 Sep. 2004, CL No 136, 25 Aug. 2010.

Legislative Decree No 373, 26 September 2013. Official Gazette of the Federative Republic of Brazil, Brasília, DF, n 187, 26 September 2013, Section 1: 1-2.

Bueger, Christian. 2013. 'Communities of Security Practice at Work? The Emerging African Maritime Security Regime'. African Security, 6 (3-4): 297-316.

Cable, James. 1977. Diplomacía de Cañoneras. Buenos Aires: Instituto de Publicaciones Navales.

Chapsos, Ioannis and Cassie Kitchen. 2015. Strengthening Maritime Security Through Cooperation. s.l.: IOS Press.

Chatham House. 2013. 'Maritime Security in the Gulf of Guinea. [Online]. At: https://www.chathamhouse.org/sites/files/chathamhouse/public/Research/Africa/0312confreport_maritimesecurity.pdf. [Accessed on 2 June 2016].

Contipelli, Emani and Simona Picciau. 2015. 'Institutional Status of BRICS and Pragmatic Cooperation: The Case of South America'. International Organisations Research Journal, 10 (2): 160-171.

Dorman, Andrew and Joyce Kaufman (eds). 2010. The Future of Transatlantic Relations: Perceptions, Policy and Practice. Stanford: Stanford Security Studies.

Gopalakrishnan, Chennat (ed). 2000. Classic Papers in Natural Resource Economics. London: Macmillan Press.

Grove, Eric. 1990. The Future of Sea Power. 1st ed. Annapolis: U.S. Naval Institute.

Hurrel, Andrew. 1998. 'An Emerging Security Community in South America?' In Emanuel Adler and Michael Barnett (eds), Security Communities. Cambridge: Cambridge University Press.

Le Mière, Christian. 2014. Maritime Diplomacy in the 21st Century: Drivers and Challenges. New York: Routledge.

Luke, Ivan T. 2013. 'Naval Operation in Peacetime: Not Just Warfare Lite'. Naval War College Review, 2 (66): 10-26.

McNicholas, Michael. 2007. Maritime Security: An Introduction. Homeland Security Series. London: Butterworth-Heinemann.

. 2016. Maritime Security - An introduction. 2nd ed. Cambridge: Butterworth-Heinemann (an imprint of Elsevier).

Medeiros, Sabrina E. 2015. 'Maritime Coordination and Inter-American Cooperation'. CIMSEC, 7 April [online]. At: http://cimsec.org/maritime-coordination-and-inter-american-cooperation-inthe-south/15752. [Accessed on 6 April 2016].

2011. 'Models of international reputation and foreign policy paradigms'. Contexto Internacional, 33 (2): 435-453.

Moreira, William de Sousa. 1997. El Poder Naval en America del Sur Atlantica: tendências y perspectivas en el enfoque de la planificación de fuerzas. Caracas: Universidad Central de Venezuela.

2016. 'O Atlântico Sul: Segurança, Defesa e desafios tecnológicos'. In: Érica C A Winand, Thiago Rodrigues and Sérgio Luiz Cruz Aguilar (eds), Defesa e Segurança do Atlântico Sul: VIII ENABED. 1 ed. São Cristóvão: UFS, pp. 23-34. 
Nordquist, Myron H and John Norton. 1999. Current Maritime Issues and the International Maritime Organization. London: Martinus Nijhoff.

Oleksandr, Pavliuk and Ivanna Klympush-Tsintsadze. 2004. The Black Sea Region: Cooperation and Security Building. New York: M. E. Sharpe.

Otto, Lisa. 2015. 'Maritime Crime in Nigeria and Waters Beyond: Analysing the Period 2009-2013'. Africa Insight 45, June: 15-29.

Rohde, Joachim and Andrew James. 2004. The Future of Transatlantic Armaments Co-operation. Berlin: SWP.

Sanders, Deborah. 2014. Maritime Power in the Black Sea. Surrey, England: Ashgate.

Seabra, Pedro. 2016. 'Defence cooperation between Brazil and Namibia: enduring ties across the South Atlantic'. South African Journal of International Affairs, 23: 89-106.

Skinner, Andrew. 1988. Adam Smith and Economic Liberalism. Edinburgh: The David Hume Institute.

Sousa, Inês. 2014. 'Maritime Territorial Delimitation and Maritime Security in the Atlantic'. Paper presented at the ATLANTIC FUTURE Workshop, University of Pretoria, 7 June 2014.

Till, Geoffrey. 1994. Seapower: Theory and Practice. Essex: Frank Cass \& Co.

2006. 'Poder Marítimo: questões relevantes e desafios'. Revista da Escola de Guerra Naval, 7 (1): 8-31.

2013. Seapower: A Guide for the Twenty-First Century. 3rd ed. New York: Routledge.

Wambua, Paul M. 2009. 'Enhancing regional maritime cooperation in Africa: The planned end state'. African Security Studies, 18 (3): 45-59.

Wenger, Etienne and William Snyder. 2000. 'Communities of Practice: The Organizational Frontier. Harvard Business Review, January-February: 139-145.

\section{Acknowledgements}

The authors would like to thank the Brazilian Ministries of Education (CAPES/MEC) and Defence for their support of the research programme "PRODEFESA III". The concepts and thoughts presented in this article express the authors' own ideas and do not represent any official thinking or positions held by the institutions they are affiliated to.

\section{About the authors}

Sabrina Evangelista Medeiros is Associate Professor at the Brazilian Naval War College (Escola de Guerra Naval - EGN, Rio de Janeiro) and was a member of the Inter-American Defense College faculty between July 2013 and July 2015. She has a Bachelorss and a Masterıs Degree from Rio de Janeiro Federal University (UFRJ). She received her PhD in Political Science from the IUPERJ and received an Honourable Mention from the Asociación Latino Americana de Ciencia Política (ALACIP) for her PhD thesis. Presently, she is the Vice-coordinator of the Postgraduate Programme in Maritime Studies, and the leading researcher of the Simulation and Scenarios Laboratory at EGN. 
William de Sousa Moreira, Navy Captain (Ret.), is Professor at the Brazilian Naval War College (Escola de Guerra Naval - EGN, Rio de Janeiro) and the Co-ordinator of the Postgraduate Programme in Maritime Studies (PPGEM-EGN). He is the Science, Technology, and Innovation Advisor of EGN and a researcher at the Centre for Political and Strategic Studies. He received his PhD in Political Science from the Fluminense Federal University (UFF), where he is a member of the research group Defence Industry and Political Power Laboratory, at UFF's Institute for Strategic Studies. He currently researches science and military technology trends and impacts on maritime security, strategy, and force planning, with a focus on South Atlantic region.

Received on 4 July 2016 and approved for publication on 20 February 2017.

\section{(cc) BY-NC} https://creativecommons.org/licenses/by-nc/4.0/ 